\title{
Prevalence of Diabetes and Prediabetes in Adults from a Third-Tier City in Eastern China: A Cross- Sectional Study
}

\author{
Yuan Song - Xiaomei Zhang · Hengyan Zhang - Qingqing Yang · \\ Shirong Zhang · Yadi Zhang · Yufei Chen · Yingchun Ji • \\ Xiaolei $\mathrm{Hu}$ (D)
}

Received: April 15, 2019 / Published online: June 28, 2019

(c) The Author(s) 2019

\begin{abstract}
Introduction: The aims of this study were to investigate the prevalence of adult diabetes and prediabetes in Bengbu (eastern China) in 2017, and to identify measures that can be taken to reduce the prevalence of diabetes and prediabetes in this region.
\end{abstract}

Yuan Song and Xiaomei Zhang contributed equally to this work.

Enhanced Digital Features To view enhanced digital features for this article go to https://doi.org/10.6084/ m9.figshare.8263844.

Y. Song $\cdot$ X. Zhang $\cdot$ H. Zhang $\cdot$ Q. Yang

Y. Zhang $\cdot \mathrm{X} . \mathrm{Hu}(\bowtie)$

Department of Endocrinology, The First Affiliated Hospital of Bengbu Medical College, Bengbu, Anhui, China

e-mail: caesar80@163.com

S. Zhang

Laboratory of the Endocrinology Department, The First Affiliated Hospital of Bengbu Medical College, Bengbu, Anhui, China

\section{Y. Chen}

Department of Gastroenterology, The First Affiliated Hospital of Bengbu Medical College, Bengbu, Anhui, China

Y. Ji

Department of Respiratory, The First Affiliated Hospital of Bengbu Medical College, Bengbu, Anhui, China
Methods: A stratified cluster random sampling method was used in the study. Two sampling sites were randomly selected from each of the four districts of Bengbu City, and all permanent residents (resident for $\geq 5$ years) at all eight sampling sites aged 18 years or above were cluster sampled, which led to the sampling of 3388 adults. After screening, a total of 3144 respondents were enrolled in the study. The $t$ test was utilized to compare the mean parameter values of the males and the females, and variance analysis was employed to compare the mean values of the nondiabetic, prediabetic, and diabetic groups. The chi-squared test was used to compare rates. Logistic regression was used for multivariate analysis, and the statistical significance level $\alpha$ was set to 0.05 .

Results: The mean ages of the male and female groups were $51.1 \pm 15.7$ and $49.4 \pm 15.1$ years, respectively $(p<0.05)$. The diabetes prevalence in adults was $11.5 \%(8.4 \%$ after standardization), while the prevalence of prediabetes in adults was $32.0 \%$ (27.6\% after standardization). The prevalence of diabetes and that of prediabetes gradually increased with age (both $p<0.05)$. Older age, hypertension, overweight status, obesity, central obesity, current smoker status, low serum high-density lipoprotein level, and high serum low-density lipoprotein level were all significantly associated with a higher risk of diabetes $(p<0.05)$.

Conclusion: The prevalence of diabetes and that of prediabetes in adults in Bengbu City 
remain high. Intervention aimed at reducing the occurrence of diabetic complications and preventing prediabetes from further development is urgently required.

Keywords: Diabetes; Epidemiology; Prediabetes; Prevalence rate; Risk factors

\section{INTRODUCTION}

Diabetes mellitus (DM) is one of most common metabolic disorders in the world, and the prevalence of diabetes in adults has been increasing globally over the last few decades $[1,2]$. According to a report from the International Diabetes Federation, there were estimated to be 451 million people (aged 18-99 years) with diabetes worldwide in 2017 [3]. These figures are expected to increase to 693 million by 2045 [3]. Epidemiological investigations of diabetes in China began in the 1980s, and were conducted in 1980, 1994, 2007, 2010, and 2013. In 2010 , the prevalence of diabetes was $11.6 \%$ in Chinese adults aged $\geq 18$ years, and the prevalence of prediabetes was $50.1 \%$ [4]. In 2013, the estimated standardized prevalence of diagnosed and undiagnosed diabetes in the adult Chinese population was $10.9 \%$, while the prevalence of prediabetes was $35.7 \%$ [5]. Diabetes and its chronic complications pose a great threat to the lives and the quality of life of patients, and impose direct, indirect, and intangible economic burdens on their families, the entire health system, and the country. In 2014, diabetes-related medical services consumed 80.33 billion yuan, representing 5\% of the medical resources directed towards chronic diseases, and $33.99 \%$ of the medical expenses of diabetes were paid for by families [6]. Therefore, it is important to determine the prevalence of diabetes and prediabetes and to prevent and control diabetes and prediabetes.

While the prevalence of diabetes and that of prediabetes in the adult Chinese population have been reported, China is a large country, with the gap between rich and poor and the lifestyles adopted in different regions varying greatly. As a result, the prevalence of diabetes also varies widely between regions. Bengbu is a third-tier city in eastern China that has a developed economy. Our research group has conducted a series of studies on the prevention and treatment of diabetes in Bengbu [7-14]. In October 1979, we attended the First National Conference on Diabetes Research, held in Lanzhou. In 1980, a general survey of diabetes was carried out for the first time in Bengbu, and a tertiary diabetes prevention network was established. In 1994, we took part in the National Diabetes Prevention and Control of Cooperative Group [15], carried out a second diabetes census, and conducted a series of prevention and control studies and comparative analyses. Similarly, in 2005, we conducted a third diabetes status survey in Bengbu. That and the previous two surveys of residents diagnosed with diabetes and abnormal glucose tolerance were used to conduct a comprehensive study of diabetes prevention and treatment over the last 25 years. Over the last decade or more, the rapid development of the national economy, improvements in living standards, changes in diet, and a reduction in the amount of physical exercise performed by the general population have led to a rapid increase in the incidence of diabetes. By investigating the prevalence and risk factors of diabetes and prediabetes in Bengbu, we can not only improve the health of local residents but also provide guidance for local governments who are attempting to implement effective regional chronic disease prevention and control strategies.

Therefore, we conducted a population sampling survey of permanent residents ( $\geq 5$ years resident) of the Bengbu area aged 18 years or more in order to explore the characteristics of the adult diabetics and prediabetics in Bengbu and to pinpoint risk factors for diabetes. The results should facilitate work aimed at identifying measures that could be taken to prevent and control diabetes in adults.

\section{METHODS}

\section{Subjects}

Stratified cluster random sampling was used in the study. Prior to this sampling, a list of all the 
sites at which sampling was to be performed was established, based on the distribution discussed in our previous study [7]. Two sampling sites were randomly selected from each of the four districts (Yuhui District, Bengshan District, Longzihu District, and Huaishang District) of Bengbu City. All permanent residents (only persons who had been living in Bengbu for at least 5 years) at the eight sampling sites (one hospital, one bank, one middle school, one university, two government institutions, and two factories) who were $\geq 18$ years old were cluster sampled, resulting in the sampling of 3388 adults. The following subjects were removed: (1) those with severe liver and kidney diseases, acute diseases, infectious diseases, or trauma surgery; (2) those who did not answer the questionnaire in a consistent manner; and (3) those with incomplete data on physical or biochemical indicators. This led to the removal of 244 people from the study, leaving 3144 adults. The sampling efficiency was $92.8 \%$. Among the respondents, 1655 were males and 1489 were females, and all respondents provided written informed consent. The protocol for the research project was approved by the Institutional Review Board and Ethics Committee of The First Affiliated Hospital of Bengbu Medical College (no. BYYFY-2017.KY04) and conforms to the Helsinki Declaration of 1964 and its later amendments. All subjects gave their informed consent and patient anonymity is preserved within the text of this manuscript.

\section{Methods}

A questionnaire focusing on demographic characteristics (age, sex, education, etc.), medical history, and lifestyle factors was administered by a trained medical worker. A current smoker was defined as someone who had smoked at least 100 cigarettes in their lifetime and still smoked cigarettes. Anthropometric measurements included height, weight, waist circumference (WC), and hip circumference. The body mass index (BMI) was also calculated.

The diagnostic criteria for diabetes and prediabetes were those proposed by the American Diabetes Association (ADA) in 2010 [16]. A diabetic was defined as someone with (1) a selfreported previous diagnosis of diabetes, (2) a fasting plasma glucose (FPG) level of $7.0 \mathrm{mmol} /$ L or higher, (3) a 2-h plasma glucose level of $11.1 \mathrm{mmol} / \mathrm{L}$ or higher, or (4) a glycosylated hemoglobin A1c (HbA1c) concentration of $6.5 \%$ or more (i.e., if one or more of these criteria were met, the individual was categorized as diabetic). A prediabetic and someone at an increased risk of diabetes were defined as individuals with (1) $\quad F P G \geq 5.6 \mathrm{mmol} / \mathrm{L}$ and $<7.0 \mathrm{mmol} / \mathrm{L}$, (2) 2-h plasma glucose levels of $\geq 7.8 \mathrm{mmol} / \mathrm{L}$ and $<11.1 \mathrm{mmol} / \mathrm{L}$, respectively, or (3) a HbA1c concentration of $\geq 5.7 \%$ and $<6.5 \%$, participants without a prior diagnosis of diabetes. If the individual met one or more of these criteria, they were categorized as prediabetic. In this study, FPG and HbA1c were used together to diagnose diabetes and prediabetes. Any individual who met the appropriate diagnostic criteria based on FPG and HbA1c was diagnosed accordingly as a diabetic or a prediabetic. BMI was used to classify individuals as overweight (BMI $24.0-27.9 \mathrm{~kg} / \mathrm{m}^{2}$ ) or obese $\left(\mathrm{BMI} \geq 28.0 \mathrm{~kg} / \mathrm{m}^{2}\right.$ ) [17]. The diagnostic criteria for dyslipidemia included serum total cholesterol (TC) $\geq 6.2 \mathrm{mmol} / \mathrm{L}, \quad$ low-density lipoprotein $(\mathrm{LDL}) \geq 4.1 \mathrm{mmol} / \mathrm{L}$, high-density lipoprotein $(\mathrm{HDL})<1.0 \mathrm{mmol} / \mathrm{L}, \quad$ and triglyceride (TG) $\geq 2.3 \mathrm{mmol} / \mathrm{L}$ [18]. Central obesity was defined as a male with $\mathrm{WC} \geq 90 \mathrm{~cm}$ and a female with $W C \geq 80 \mathrm{~cm}$ [19]. The diagnostic criterion for hyperuricemia (HUA) was based on blood uric acid: $>420 \mu \mathrm{mol} / \mathrm{L}$ for males and $>360 \mu \mathrm{mol} / \mathrm{L}$ for females [20].

SPSS 24.0 (IBM, Chicago, IL, USA) was used for data processing and for all data analyses. Measurement data were expressed in terms of the mean and standard deviation. The $t$ test was utilized to compare the mean values of the males to those of the females, and variance analysis was adopted to compare the means of the nondiabetic, prediabetic, and diabetic groups. The chi-squared test was used to compare rates. Logistic regression was used for multivariate analysis, and the statistical significance level $(\alpha)$ was set to 0.05. Additionally, prevalence was standardized according to the 
age structure of the Sixth National Census in 2010.

\section{RESULTS}

The clinical characteristics of the participants are shown in Table 1 . Among the 3144 participants, 1776 were nondiabetic individuals, 1007 had prediabetes, and 361 had diabetes. The mean ages of the nondiabetic, prediabetic, and diabetic participants were $45.9 \pm 14.4$, $54.3 \pm 14.8$, and $60.5 \pm 14.0$ years (mean \pm SD values; $p<0.001$ ), respectively. The prevalence rate of hypertension, proportion of males and current smokers, BMI, WC, hip circumference, TC, LDL, TG, uric acid (UA) increased with elevated blood glucose levels $(p<0.001)$ and HDL decreased with it $(p<0.001)$.

In this study, a total of 3388 people were investigated, but there were 244 with incomplete laboratory and demographic data, so the actual effective number of participants was 3144 (the effective sampling rate was 92.8\%).
The prevalence of diabetes in adults was $11.5 \%$ (8.4\% after standardization). The prevalence rate of prediabetes in adults was 32.0\% $(27.6 \%$ after standardization) (see Tables 2, 3).

The prevalence rates of diabetes in male and female adults were $13.7 \%$ and $9.1 \%$, respectively $(13.3 \%$ and $9.3 \%$, respectively, after standardization). This difference was statistically significant $\quad\left(\chi^{2}=16.241, \quad p<0.05\right)$ (Tables 2,3). There were a total of 1655 males with an average age of $51.1 \pm 15.7$ years, and 1489 females with an average age of $49.4 \pm 15.1$ years. The difference in the average ages of the males and females was statistically significant $(t=3.106, p<0.05)$. The prevalence rates of diabetes and prediabetes gradually increased with age $\left(\chi^{2}=169.746, p<0.05\right.$ and $\chi^{2}=111.013, \quad p<0.05, \quad$ respectively). The prevalence of diabetes in males of all ages was consistently higher than it was in females of all ages. In addition, the prevalence of prediabetes in males under 50 years old was higher than that in females under 50 years old, and the prevalence of prediabetes in females over the

Table 1 General characteristics of the participants

\begin{tabular}{lllll}
\hline Variable & $\begin{array}{l}\text { Nondiabetic group } \\
\boldsymbol{n}=\mathbf{1 7 7 6}\end{array}$ & $\begin{array}{l}\text { Prediabetic group } \\
\boldsymbol{n}=\mathbf{1 0 0 7}\end{array}$ & $\begin{array}{l}\text { Diabetic group } \\
\boldsymbol{n}=\mathbf{3 6 1}\end{array}$ & $\boldsymbol{p}$ value \\
\hline Male sex (\%) & $49.1 \%$ & $55.3 \%$ & $62.6 \%$ & $<0.001$ \\
Age (years) & $45.9 \pm 14.4$ & $54.3 \pm 14.8$ & $60.5 \pm 14.0$ & $<0.001$ \\
GLU $(\mathrm{mmol} / \mathrm{L})$ & $5.00 \pm 0.41$ & $5.80 \pm 0.47$ & $8.82 \pm 2.60$ & $<0.001$ \\
BMI $\left(\mathrm{kg} / \mathrm{m}^{2}\right)$ & $23.1 \pm 2.9$ & $24.6 \pm 3.6$ & $25.5 \pm 3.7$ & $<0.001$ \\
Waist circumference $(\mathrm{cm})$ & $81.6 \pm 9.8$ & $86.6 \pm 10.9$ & $89.8 \pm 10.2$ & $<0.001$ \\
Hip circumference $(\mathrm{cm})$ & $93.5 \pm 10.3$ & $96.5 \pm 10.4$ & $97.2 \pm 11.0$ & $<0.001$ \\
TC $(\mathrm{mmol} / \mathrm{L})$ & $4.79 \pm 0.91$ & $4.99 \pm 0.95$ & $5.04 \pm 1.07$ & $<0.001$ \\
HDL $(\mathrm{mmol} / \mathrm{L})$ & $1.41 \pm 0.38$ & $1.30 \pm 0.37$ & $1.25 \pm 0.36$ & $<0.001$ \\
LDL $(\mathrm{mmol} / \mathrm{L})$ & $2.53 \pm 0.69$ & $2.72 \pm 0.75$ & $2.73 \pm 0.82$ & $<0.001$ \\
TG $(\mathrm{mmol} / \mathrm{L})$ & $1.57 \pm 1.15$ & $1.76 \pm 1.02$ & $2.15 \pm 1.93$ & $<0.001$ \\
UA $(\mu \mathrm{mol} / \mathrm{L})$ & $316 \pm 88$ & $334 \pm 83$ & $322 \pm 82$ & $<0.001$ \\
Hypertension $(\%)$ & $17.5 \%$ & $24.5 \%$ & $31.3 \%$ & $<0.001$ \\
Current smoking $(\%)$ & $23.3 \%$ & $34.4 \%$ & $39.9 \%$ & $<0.001$ \\
\hline
\end{tabular}

$G L U$ glucose, $B M I$ body mass index, $T C$ serum total cholesterol, $H D L$ high-density lipoprotein, $L D L$ low-density lipoprotein, $T G$ triglyceride, $U A$ uric acid 
Table 2 Risk factors for diabetes in the adult population of Bengbu

\begin{tabular}{|c|c|c|c|c|c|}
\hline & $\begin{array}{l}\text { Total number of } \\
\text { participants }\end{array}$ & $\begin{array}{l}\text { Total number with } \\
\text { diabetes }\end{array}$ & $\begin{array}{l}\text { Diabetes prevalence } \\
\text { (\%) }\end{array}$ & $\chi^{2}$ & $\overline{p \text { value }}$ \\
\hline Overall & 3144 & 361 & 11.5 & & \\
\hline Sex & & & & 16.241 & $<0.001$ \\
\hline Men & 1655 & 226 & 13.7 & & \\
\hline Women & 1489 & 135 & 9.1 & & \\
\hline BMI $\left(\mathrm{kg} / \mathrm{cm}^{2}\right)$ & & & & 105.911 & $<0.001$ \\
\hline$<24.0$ (normal) & 1731 & 125 & 7.2 & & \\
\hline $\begin{array}{l}24.0-27.9 \\
\text { (overweight) }\end{array}$ & 1078 & 149 & 13.8 & & \\
\hline$\geq 28$ (obese) & 335 & 87 & 26.0 & & \\
\hline $\begin{array}{l}\text { Waist circumference } \\
(\mathrm{cm})\end{array}$ & & & & 60.336 & $<0.001$ \\
\hline$<90$ in men & 1792 & 137 & 7.6 & & \\
\hline$<80$ in women & & & & & \\
\hline $\begin{array}{l}\geq 90 \text { in men } \\
\geq 80 \text { in women }\end{array}$ & 1352 & 224 & 16.6 & & \\
\hline $\mathrm{UA}(\mu \mathrm{mol} / \mathrm{L})$ & & & & 0.876 & 0.349 \\
\hline $\begin{array}{l}\leq 420 \text { in men } \\
\leq 360 \text { in women }\end{array}$ & 2615 & 294 & 11.2 & & \\
\hline $\begin{array}{l}>420 \text { in men } \\
>360 \text { in women }\end{array}$ & 529 & 67 & 12.7 & & \\
\hline $\mathrm{TC}(\mathrm{mmol} / \mathrm{L})$ & & & & 11.156 & 0.001 \\
\hline$<6.2$ & 2851 & 310 & 10.9 & & \\
\hline$\geq 6.2$ & 293 & 51 & 17.4 & & \\
\hline $\mathrm{TG}(\mathrm{mmol} / \mathrm{L})$ & & & & 22.761 & $<0.001$ \\
\hline$<2.3$ & 2598 & 266 & 10.2 & & \\
\hline$\geq 2.3$ & 546 & 95 & 17.4 & & \\
\hline $\mathrm{LDL}(\mathrm{mmol} / \mathrm{L})$ & & & & 15.670 & $<0.001$ \\
\hline$<4.1$ & 2971 & 325 & 10.9 & & \\
\hline$\geq 4.1$ & 173 & 36 & 20.8 & & \\
\hline $\mathrm{HDL}(\mathrm{mmol} / \mathrm{L})$ & & & & 28.746 & $<0.001$ \\
\hline$\geq 1.0$ & 2598 & 262 & 10.1 & & \\
\hline$<1.0$ & 546 & 99 & 18.1 & & \\
\hline
\end{tabular}


Table 2 continued

\begin{tabular}{|c|c|c|c|c|c|}
\hline & $\begin{array}{l}\text { Total number of } \\
\text { participants }\end{array}$ & $\begin{array}{l}\text { Total number with } \\
\text { diabetes }\end{array}$ & $\begin{array}{l}\text { Diabetes prevalence } \\
(\%)\end{array}$ & $\chi^{2}$ & $p$ value \\
\hline Level of education & & & & 55.578 & $<0.001$ \\
\hline None & 191 & 35 & 18.3 & & \\
\hline Primary school & 208 & 44 & 21.2 & & \\
\hline Junior high school & 701 & 105 & 15.0 & & \\
\hline Senior high school & 720 & 74 & 10.3 & & \\
\hline College/university & 938 & 70 & 7.5 & & \\
\hline$\geq$ Master & 386 & 33 & 8.5 & & \\
\hline Current smoker & & & & 24.688 & $<0.001$ \\
\hline No & 2240 & 217 & 9.7 & & \\
\hline Yes & 904 & 144 & 15.9 & & \\
\hline Hypertension & & & & 24.279 & $<0.001$ \\
\hline No & 2474 & 248 & 10.0 & & \\
\hline Yes & 670 & 113 & 16.9 & & \\
\hline
\end{tabular}

$B M I$ body mass index, $T C$ serum total cholesterol, $H D L$ high-density lipoprotein, $L D L$ low-density lipoprotein, $T G$ triglyceride, $U A$ uric acid

age of 50 years was higher than that in males over the age of 50 years (Fig. 1).

In the single factor analysis, the prevalence rates of diabetes and prediabetes were found to increase significantly with increasing BMI $\left(\chi^{2}=105.911, \quad p<0.05\right.$ and $\chi^{2}=56.451$, $p<0.05$, respectively). The prevalence of diabetes in patients with central obesity (male WC $\geq 90 \mathrm{~cm}$ and female $\mathrm{WC} \geq 80 \mathrm{~cm}$ ) was $16.6 \%$, which was significantly higher than that in the normal WC group $(7.6 \%) \quad\left(\chi^{2}=60.336\right.$, $p<0.05)$; the prediabetes prevalence was $40.5 \%$, which was higher than the prediabetes prevalence observed in the normal WC group $(25.6 \%)$, and this difference was statistically significant $\left(\chi^{2}=78.782, p<0.05\right)$. Among other factors affecting diabetes, people who differed in TC, TG, HDL, LDL, education level, history of hypertension, and smoking status had different prevalence rates of diabetes, and people who differed in TC, HDL, LDL, UA, education level, history of hypertension, and smoking status had different prevalence rates of prediabetes $(p<0.05)$ (Tables 2, 3).

In a multinomial logistic regression model, older age, hypertension, overweight status, obesity, central obesity, current smoker status, low serum HDL level, and high serum LDL level were all significantly associated with a higher risk of diabetes $(p<0.05)$, and a higher level of education was inversely associated with diabetes. In addition, older age, hypertension, obesity, central obesity, current smoker status, low serum HDL level, and elevated serum LDL level were positively associated with a higher risk of prediabetes $(p<0.05)$, while a higher level of education was inversely associated with prediabetes (Table 4).

\section{DISCUSSION}

This epidemiological investigation of adult diabetes and prediabetes in Bengbu City showed that the prevalence of adult diabetes in Bengbu 
Table 3 Risk factors for prediabetes in the adult population of Bengbu

\begin{tabular}{|c|c|c|c|c|c|}
\hline & $\begin{array}{l}\text { Total number of } \\
\text { participants }\end{array}$ & $\begin{array}{l}\text { Total number with } \\
\text { prediabetes }\end{array}$ & $\begin{array}{l}\text { Prediabetes } \\
\text { prevalence (\%) }\end{array}$ & $\chi^{2}$ & $\overline{p \text { value }}$ \\
\hline Overall & 3144 & 1007 & 32.0 & & \\
\hline Sex & & & & 4.246 & 0.039 \\
\hline Men & 1655 & 557 & 33.7 & & \\
\hline Women & 1489 & 450 & 30.2 & & \\
\hline BMI $\left(\mathrm{kg} / \mathrm{cm}^{2}\right)$ & & & & 56.451 & $<0.001$ \\
\hline$<24.0$ (normal) & 1731 & 468 & 27.0 & & \\
\hline $\begin{array}{l}24.0-27.9 \\
\text { (overweight) }\end{array}$ & 1078 & 385 & 35.7 & & \\
\hline$\geq 28$ (obese) & 335 & 154 & 46.0 & & \\
\hline $\begin{array}{l}\text { Waist circumference } \\
\qquad(\mathrm{cm})\end{array}$ & & & & 78.782 & $<0.001$ \\
\hline$<90$ in men & 1792 & 459 & 25.6 & & \\
\hline$<80$ in women & & & & & \\
\hline $\begin{array}{l}\geq 90 \text { in men } \\
\geq 80 \text { in women }\end{array}$ & 1352 & 548 & 40.5 & & \\
\hline $\mathrm{UA}(\mu \mathrm{mol} / \mathrm{L})$ & & & & 5.316 & 0.021 \\
\hline $\begin{array}{l}\leq 420 \text { in men } \\
\leq 360 \text { in women }\end{array}$ & 2615 & 815 & 31.2 & & \\
\hline $\begin{array}{l}>420 \text { in men } \\
>360 \text { in women }\end{array}$ & 529 & 192 & 36.3 & & \\
\hline $\mathrm{TC}(\mathrm{mmol} / \mathrm{L})$ & & & & 12.747 & $<0.001$ \\
\hline$<6.2$ & 2851 & 886 & 31.1 & & \\
\hline$\geq 6.2$ & 293 & 121 & 41.3 & & \\
\hline $\mathrm{TG}(\mathrm{mmol} / \mathrm{L})$ & & & & 1.753 & 0.186 \\
\hline$<2.3$ & 2598 & 819 & 31.5 & & \\
\hline$\geq 2.3$ & 546 & 188 & 34.4 & & \\
\hline $\mathrm{LDL}(\mathrm{mmol} / \mathrm{L})$ & & & & 19.865 & $<0.001$ \\
\hline$\leq 4.1$ & 2971 & 925 & 31.1 & & \\
\hline$>4.1$ & 173 & 82 & 47.4 & & \\
\hline $\mathrm{HDL}(\mathrm{mmol} / \mathrm{L})$ & & & & 24.564 & $<0.001$ \\
\hline$\geq 1.0$ & 2598 & 783 & 30.1 & & \\
\hline$<1.0$ & 546 & 224 & 41.0 & & \\
\hline
\end{tabular}


Table 3 continued

\begin{tabular}{|c|c|c|c|c|c|}
\hline & $\begin{array}{l}\text { Total number of } \\
\text { participants }\end{array}$ & $\begin{array}{l}\text { Total number with } \\
\text { prediabetes }\end{array}$ & $\begin{array}{l}\text { Prediabetes } \\
\text { prevalence }(\%)\end{array}$ & $\chi^{2}$ & $p$ value \\
\hline Level of education & & & & 67.121 & $<0.001$ \\
\hline None & 191 & 98 & 51.3 & & \\
\hline Primary school & 208 & 97 & 46.6 & & \\
\hline Junior high school & 701 & 234 & 33.4 & & \\
\hline Senior high school & 720 & 209 & 29.0 & & \\
\hline College/university & 938 & 263 & 28.0 & & \\
\hline$\geq$ Master & 386 & 106 & 27.5 & & \\
\hline Current smoker & & & & 22.731 & $<0.001$ \\
\hline No & 2240 & 661 & 29.5 & & \\
\hline Yes & 904 & 346 & 38.3 & & \\
\hline Hypertension & & & & 9.148 & 0.002 \\
\hline No & 2474 & 760 & 30.7 & & \\
\hline Yes & 670 & 247 & 36.9 & & \\
\hline
\end{tabular}

$B M I$ body mass index, $T C$ serum total cholesterol, $H D L$ high-density lipoprotein, $L D L$ low-density lipoprotein, $T G$ triglyceride, $U A$ uric acid

was $11.5 \%$ (8.4\% after standardization), which was lower than the prevalence of $10.9 \%$ found during the National Adult Diabetes Investigation in 2013 [5]. This difference may be related to the geographical location of Bengbu (eastern China) and its developed economy. Furthermore, the sample comprised urban residents with a relatively high population quality. However, the prevalence of diabetes was significantly higher than those reported in the three previous epidemiological investigations of diabetes in Bengbu City conducted by our research group (the prevalence was $0.85 \%$ in $1980,2.63 \%$ in 1994 , and $7.5 \%$ in $2005-2006$ ) [7], which may be closely related to the remarkable improvement in living standards and the changes in diet (more calories, fat, sugar, and sodium), lifestyle (decreased physical activity), and work pressure that have occurred over the past few decades.

This investigation showed that the prevalence rate of adult prediabetes was $32.0 \%$ (27.6\% after standardization), which is similar to the prevalence of $35.7 \%$ noted in the 2013 Chinese survey [5] and the prevalence of $36.5 \%$ observed in an epidemiological investigation of prediabetes in the United States in 2011-2012 [21]. This finding shows that prediabetes has become an important hidden danger to human health and quality of life, and one in three of the population reach the diagnostic standard for prediabetes, which is an important risk factor for diabetes and systemic macrovascular and microvascular diseases as well as subsequent diseases of the kidney, heart, brain, and other organs. According to epidemiological investigations in China, diabetic nephropathy has surpassed glomerulonephritis to become the leading cause of hospitalization for patients with chronic kidney disease (CKD) [22], and diabetic retinopathy has also become the most common cause of adult blindness [23]. Therefore, it is necessary to strengthen the control of blood glucose in diabetic patients and to ensure that people with prediabetes and diabetes 
A Diabetes

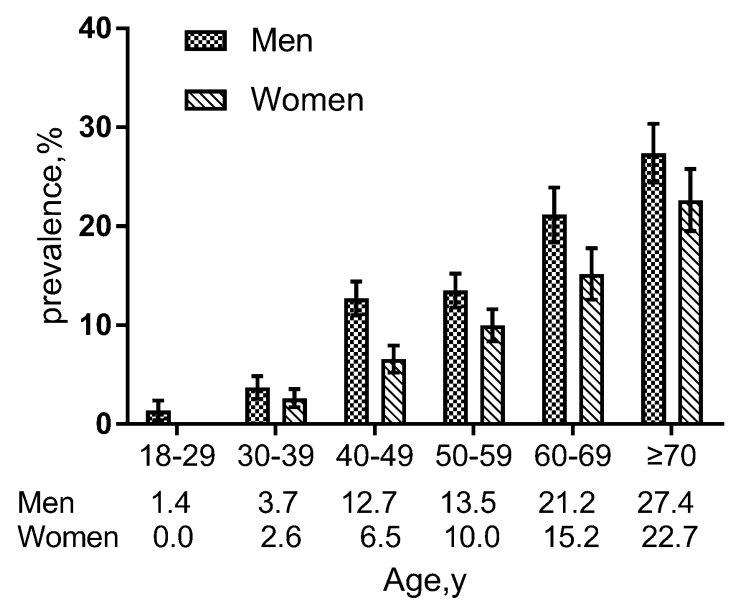

B

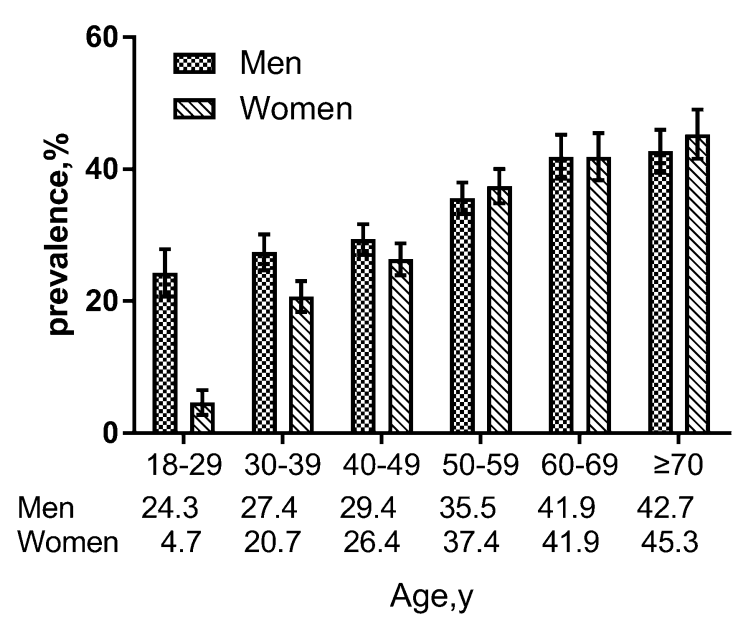

Fig. 1 Age-specific and age-standardized prevalence rates of diabetes and prediabetes in Bengbu adults aged 18 years or older in 2017. Error bars indicate 95\% confidence intervals

understand the important roles played by diet and sports in blood glucose control.

In addition, this investigation showed that the male proportion of the population, age, BMI, WC, hip circumference, TC, LDL, and TG, as well as the prevalence rates of hypertension and smoking are on the rise with elevated blood glucose levels $(p<0.001)$. In the single-factor study, BMI, central obesity, TC, TG, LDL, HDL, smoking status, hypertension, and level of education were significantly associated with the prevalence rates of diabetes and prediabetes $(p<0.05)$. In a multinomial logistic regression model, older age, hypertension, overweight status, obesity, central obesity, current smoker status, lower serum HDL level, and elevated serum LDL and triglyceride levels were risk factors for diabetes, while a higher level of education was a protective factor against diabetes. Older age, hypertension, obesity, central obesity, current smoker status, lower serum HDL level, and elevated serum LDL level were risk factors for prediabetes, while a higher level of education was a protective factor against prediabetes, which is consistent with the findings of other studies on diabetes and obesity [24]. Additionally, the prevalence rates of diabetes and prediabetes in males were higher than those in females $(p<0.05)$, which may be related to the risk factors for diabetes, such as smoking, drinking, irregular work and rest, dyslipidemia, etc. This provides another reminder that maintaining a healthy lifestyle, increasing exercise levels, and eating a balanced diet are important ways to prevent and control diabetes. This study also found that the prevalence rates of diabetes and prediabetes decline with increasing education level $(p<0.001)$, which is a protective factor against diabetes. We expect that improvements in the average education level of the overall population will impact on the prevalence of diabetes, as this should coincide with a better understanding of various diseases (including diabetes) and a greater knowledge of preventive measures for diabetes among the general population.

The present study has several strengths. First, it was conducted on a large sample of the general population in Bengbu. This sample was larger than those studied in previous epidemiological investigations. Second, this study was a continuation of a series of studies we have already performed. We found how the prevalence rates of diabetes and prediabetes and therelated risk factors changed over time, which could not only improve the health condition of local residents, but also provide theoretical guidance for local governments to plan effective regional chronic disease prevention and control strategies. Third, following the ADA 2010 criteria [16], HbA1c was added to the diagnostic 
Table 4 Risk factors for diabetes and prediabetes in the participants

\begin{tabular}{|c|c|c|c|c|}
\hline Risk factor & Diabetes, OR (95\% CI) & $p$ value & Prediabetes, OR (95\% CI) & $p$ value \\
\hline Male sex & $1.177(0.890-1.557)$ & 0.253 & $0.878(0.714-1.079)$ & 0.217 \\
\hline \multicolumn{5}{|l|}{ Age (years) } \\
\hline $46-60$ & $3.046(2.148-4.319)$ & $<0.001$ & $1.885(1.549-2.294)$ & $<0.001$ \\
\hline$>60$ & $6.287(4.446-8.890)$ & $<0.001$ & $3.802(3.046-4.746)$ & $<0.001$ \\
\hline Hypertension & $1.629(1.258-2.109)$ & $<0.001$ & $1.471(1.197-1.809)$ & $<0.001$ \\
\hline$\geq$ Senior high school education & $0.619(0.488-0.785)$ & $<0.001$ & $0.597(0.500-0.714)$ & $<0.001$ \\
\hline \multicolumn{5}{|l|}{$\mathrm{BMI}^{\mathrm{a}}$} \\
\hline Overweight status & $1.397(1.041-1.875)$ & 0.026 & $1.187(0.967-1.456)$ & 0.101 \\
\hline Obesity & $2.596(1.774-3.798)$ & $<0.001$ & $2.373(1.701-3.309)$ & $<0.001$ \\
\hline Central obesity ${ }^{\mathrm{b}}$ & $1.433(1.078-1.905)$ & 0.013 & $1.802(1.475-2.202)$ & $<0.001$ \\
\hline Current smoking & $1.422(1.083-1.868)$ & 0.011 & $1.788(1.443-2.216)$ & $<0.001$ \\
\hline $\mathrm{TC} \geq 6.2 \mathrm{mmol} / \mathrm{L}$ & $1.158(0.795-1.685)$ & 0.445 & $1.263(0.923-1.728)$ & 0.145 \\
\hline $\mathrm{HDL}<1.0 \mathrm{mmol} / \mathrm{L}$ & $1.594(1.185-2.145)$ & 0.002 & $2.125(1.665-2.712)$ & $<0.001$ \\
\hline $\mathrm{LDL} \geq 4.1 \mathrm{mmol} / \mathrm{L}$ & $1.606(1.033-2.495)$ & 0.035 & $2.058(1.373-3.084)$ & $<0.001$ \\
\hline $\mathrm{TG} \geq 2.3 \mathrm{mmol} / \mathrm{L}$ & $1.348(0.989-1.838)$ & 0.059 & $0.808(0.626-1.042)$ & 0.808 \\
\hline $\mathrm{HUA}^{\mathrm{c}}$ & $0.844(0.618-1.153)$ & 0.287 & $1.106(0.875-1.397)$ & 0.401 \\
\hline
\end{tabular}

$B M I$ body mass index, $T C$ serum total cholesterol, $H D L$ high-density lipoprotein, $L D L$ low-density lipoprotein, $T G$ triglyceride, $H U A$ hyperuricemia

${ }^{a}$ Overweight status was defined as a body mass index (BMI, calculated as weight in kilograms divided by height in meters squared) of 24.0-27.9; obesity was defined as a BMI of 28.0 or higher

b Central obesity was defined as a waist circumference of $90 \mathrm{~cm}$ or more in men and $80 \mathrm{~cm}$ or more in women

${ }^{c}$ Hyperuricemia (HUA) was defined as blood uric acid of $>420 \mu \mathrm{mol} / \mathrm{L}$ in men and $>360 \mu \mathrm{mol} / \mathrm{L}$ in women

criteria for diabetes and prediabetes in this study, which provided the basis for a comprehensive understanding of the prevalence and control of adult diabetes in Bengbu. In addition, a strict quality assurance and quality control program was implemented at every phase of the study to ensure the validity and reliability of the data.

This study also has several limitations. First, we used a stratified cluster sampling method in the study rather than a completely random sampling method. This will have resulted in biased estimates. Second, we did not distinguish type 1 from type 2 diabetes in our investigation of adult diabetics, and we did not investigate the incidence of type 1 diabetes, although this accounts for less than $5 \%$ of all diabetics according to the Chinese Diabetes Clinical Guidelines [25]. Third, this study was a crosssectional study, so we could not examine the cause-and-effect relationships between some risk factors and diabetes or prediabetes. Fourth, due to the low acceptance and limited coordination of the oral glucose tolerance test (OGTT) population, we did not conduct a glucose test $2 \mathrm{~h}$ after a meal, which may have led to an underestimation of the prevalence rates of diabetes and prediabetes. However, the HbA1c test in this study was carried out in the laboratory of the Endocrinology Department of the First Affiliated Hospital of Bengbu Medical College using an ion exchange HPLC, and the test system was a reliable reference method approved by the National Glycosylated Hemoglobin 
Standardization Project (NGSP). A notable study of the Chinese population showed that the area under the receiver operating characteristic curve for detecting undiagnosed diabetes was 0.856 (95\% confidence interval $0.828-0.883$ ) for HbA1c alone and 0.920 (0.900-0.941) for fasting plasma glucose alone [26]. Furthermore, another study found that the utilization of a combination of fasting blood glucose with HbA1c to diagnose T2DM significantly improved the screening sensitivity [27]. Therefore, it is reasonable to suggest that the addition of HbA1c to the diagnostic criteria may have compensated for the abovementioned limitation of this study.

\section{CONCLUSIONS}

The prevalence of diabetes in adults in Bengbu was $11.5 \%$ (8.4\% after standardization), while that of prediabetes was $32.0 \%(27.6 \%$ after standardization), and these are largely consistent with the corresponding values for the national population. Therefore, the trend of diabetes and pre-diabetes prevalence is still severe, and early diagnosis, early treatment, and early recovery from diabetes can provide a theoretical and practical platform for the effective prevention and treatment of chronic complications.

\section{ACKNOWLEDGEMENTS}

We thank the participants of the study.

Funding. This work received the support of the National Nature Science Foundation of China (grant no. 81770803), the General Practice Clinical Research Project of Health and Family Planning Commission of Anhui Province (grant no. 2016QK021), and the Science and Technology Development Foundation of Bengbu Medical College (grant no. BYKF1832). The article processing charges were funded by the authors.

Authorship. All named authors meet the International Committee of Medical Journal
Editors (ICMJE) criteria for authorship for this article, take responsibility for the integrity of the work as a whole, and have given their approval for this version to be published.

Authorship Contributions. Yuan Song and Xiaomei Zhang wrote the manuscript. Yuan Song, Hengyan Zhang, Qingqing Yang, Yadi Zhang, Yufei Chen, and Yingchun Ji collected the data and delivered the questionnaire. Yuan Song and Xiaomei Zhang conducted the statistical analysis. Shirong Zhang detected specimens. Xiaolei $\mathrm{Hu}$ designed the study and revised the manuscript. All authors approved the final manuscript.

Disclosures. Yuan Song, Xiaomei Zhang, Hengyan Zhang, Qingqing Yang, Shirong Zhang, Yadi Zhang, Yufei Chen, Yingchun Ji, and Xiaolei $\mathrm{Hu}$ declare that there are no personal, financial, commercial, or academic conflicts of interest, and they have nothing to disclose.

Compliance with Ethics Guidelines. All procedures performed in studies involving human participants were in accordance with the ethical standards of The First Affiliated Hospital of Bengbu Medical College Committee and with the 1964 Declaration of Helsinki and its later amendments or comparable ethical standards. The ethical number is BYYFY2017.KY04. Informed consent was obtained from all individual participants included in the study.

Data Availability. The data used to support the findings of this study are available from the corresponding author upon request.

Open Access. This article is distributed under the terms of the Creative Commons Attribution-NonCommercial 4.0 International License (http://creativecommons.org/licenses/ by-nc/4.0/), which permits any noncommercial use, distribution, and reproduction in any medium, provided you give appropriate credit to the original author(s) and the source, provide a link to the Creative Commons license, and indicate if changes were made. 


\section{REFERENCES}

1. Shaw JE, Sicree RA, Zimmet PZ. Global estimates of the prevalence of diabetes for 2010 and 2030. Diabetes Res Clin Pract. 2010;87(1):4-14.

2. Whiting DR, Guariguata L, Weil C, Shaw J. IDF diabetes atlas: global estimates of the prevalence of diabetes for 2011 and 2030. Diabetes Res Clin Pract. 2011;94(3):311-21.

3. Cho NH, Shaw JE, Karuranga S, et al. IDF diabetes atlas: global estimates of diabetes prevalence for 2017 and projections for 2045. Diabetes Res Clin Pract. 2018;138:271-81.

4. Xu Y, Wang L, He J, et al. Prevalence and control of diabetes in Chinese adults. JAMA. 2013;310(9):948-59.

5. Wang L, Gao P, Zhang M, et al. Prevalence and ethnic pattern of diabetes and prediabetes in China in 2013. JAMA. 2017;317(24):2515-23.

6. Zhang Y, Wan Q, Chai P, Guo F, Wang X. The medical costs and financing burden of diabetes mellitus in China. Chin Health Econ. 2017;36(4):17-9.

7. Zhang $\mathrm{X}, \mathrm{Xu} \mathrm{H}$, Pan $\mathrm{M}$, et al. Cross-sectional investigation of prevalence of type 2 diabetes mellitus in the urban district of Bengbu. Chin J Diabetes. $2009 ; 17(4): 281-3$.

8. Xu H, Zhang X, Pan M, et al. The investigation of prevalence rates of metabolic syndrome and its related diseases in Bengbu community residents. Chin J Geriatr. 2009;28(6):509-11.

9. Zhang $\mathrm{X}, \mathrm{Xu} \mathrm{H}$, Pan $\mathrm{M}$, et al. The prognosis analysis of 30 cases with IGT after 10 years follow-up in Bengbu area. Chin J Prev Control Chronic NonCommun Dis. 2009;17(2):167-9.

10. $\mathrm{Xu} \mathrm{H}$, Zhang $\mathrm{X}$, Pan $\mathrm{M}$, et al. Data analysis of 22 subjects with IGT over 25 years follow-up in Bengbu region. Chin J Clin Healthc. 2009;12(1):33-6.

11. Zhang $\mathrm{X}$, Shi $\mathrm{Z}, \mathrm{Xu} \mathrm{H}$, et al. Outcomes of 168 patients in Bengbu 25 years after being screened out with abnormal glycometabolism. J Pract Med. 2009;25(21):3692-5.

12. $\mathrm{Xu} \mathrm{H}$, Zhang $\mathrm{X}$, Pan $\mathrm{M}$, et al. Analysis of prevention and treatment of 60 patients with type 2 diabetes mellitus in Bengbu region during the recent 10 years. J Pract Med. 2009;25(12):1960-2.

13. $\mathrm{Xu} \mathrm{H}$, Zhang $\mathrm{X}$, Pan $\mathrm{M}$, et al. Cross-sectional investigation on the prevalence of impaired glucose regulation in the urban district of Bengbu. J Pract Med. 2008;24(16):2889-91.

14. Zhang $\mathrm{X}, \mathrm{Xu} \mathrm{H}$, Pan $\mathrm{M}$, et al. Data analysis on prevention and treatment of type 2 diabetes mellitus in Bengbu area during the past 25 years. J Pract Diabetol. 2007;3(5):54-5.

15. Yang ZJ, Yang WY, Li GW, on behalf of National Diabetes Prevention and Control Cooperative Group. The distributive characteristics of impaired glucose metabolism subcategories in Chinese adult population. Natl Med J China. 2003;83(24):2128-2131.

16. American Diabetes Association. Standards of medical care in diabetes-2010. Diabetes Care. 2010;33(Suppl 1):S11-61.

17. Obese Group of Chinese Society of Endocrinology. Expert consensus on obesity prevention and control of Chinese adults. Chin J Endocrinol Metab. 2011;27(9):711-7.

18. Joint Committee for Developing Chinese guidelines on Prevention and Treatment of Dyslipidemia in Adults. Chinese guideline for the management of dyslipidemia in adults. Chin J Cardiol. 2016;44(10):833-53.

19. The World Health Organization Western Pacific Region. The Asia-Pacific perspective: redefining obesity and its treatment. 2013. http://www.wpro. who.int/nutrition/documents/docs/Redefiningobe sity.pdf. Accessed 5 Jan 2019.

20. Multidisciplinary Expert Task Force on Hyperuricemia and Related Diseases. Chinese multi-disciplinary consensus on the diagnosis and treatment of hyperuricemia and its related diseases. Chin J Intern Med. 2017;56(3):235-48.

21. Menke A, Casagrande S, Geiss L, Cowie CC. Prevalence of and trends in diabetes among adults in the United States, 1988-2012. JAMA. 2015;314(10):1021-9.

22. Zhang L, Long J, Jiang $\mathrm{W}$, et al. Trends in chronic kidney disease in China. $\mathrm{N}$ Engl $\mathrm{J}$ Med. 2016;375(9):905-6.

23. Yau JW, Rogers SL, Kawasaki R, et al. Global prevalence and major risk factors of diabetic retinopathy. Diabetes Care. 2012;35(3):556-64.

24. Eckel RH, Kahn SE, Ferrannini E, et al. Obesity and type 2 diabetes: what can be unified and what needs to be individualized? J Clin Endocrinol Metab. 2011;96(6):1654-63. 
25. Chinese Diabetes Society. China guideline for type 2 diabetes (2013 edition). Chin J Endocrinol Metab. 2014;30(10):893-942.

26. Bao Y, Ma X, Li H, et al. Glycated haemoglobin A1c for diagnosing diabetes in Chinese population: cross sectional epidemiological survey. BMJ. 2010;340:c2249.
27. Perry RC, Shankar RR, Fineberg N, et al. HbA1c measurement improves the detection of type 2 diabetes in high-risk individuals with nondiagnostic levels of fasting plasma glucose: the Early Diabetes Intervention Program (EDIP). Diabetes Care. 2001;24(3):465-71. 